\title{
Programa Prático de Modelagem de Curvas aplicado a Mazama gouazoubira (Fischer, 1814)
}

\author{
CARVALHO, Gabriela ${ }^{1}$, FREITAS, Gaby ${ }^{2}$, SOUSA, Lucio $^{3}$, CASSIANO, Rodrigo ${ }^{4}$, GARCIA-NETO, \\ Manoel $^{5}$, FILARDI, Rosemeire ${ }^{6}$
}

\footnotetext{
${ }^{1}$ Graduanda em Zootecnia - Universidade Estadual Paulista "Julio de Mesquita Filho" - UNESP, Câmpus de Ilha Solteira.

${ }^{2}$ Mestranda em Ciência e Tecnologia Animal - Universidade Estadual Paulista "Julio de Mesquita Filho" UNESP, Câmpus de llha Solteira.

${ }^{3}$ Médico Veterinário - Centro de Conservação da Fauna Silvestre de Ilha Solteira - CCFS, Ilha Solteira/SP.

${ }^{4}$ Mestrando em Ciência e Tecnologia Animal - Universidade Estadual Paulista "Julio de Mesquita Filho" UNESP, Câmpus de llha Solteira.

${ }^{5}$ Docente - Universidade Estadual Paulista "Julio de Mesquita Filho" - UNESP, Câmpus de Araçatuba.

${ }^{6}$ Docente - Universidade Estadual Paulista "Julio de Mesquita Filho" - UNESP, Câmpus de Ilha Solteira. Email: gspczootecnista@gmail.com
}

RESUMO: Descrever o crescimento não é tarefa fácil, os processos bioquímicos demandam tempo, tendo em sua dinâmica mudanças de tamanho, formato e proporções. Esse processo apresenta quatro fases: crescimento exponencial; linear; decrescente; peso estabilizado (adulto). Para justificar os diferentes comportamentos da curva, considera-se limitações nos recursos como: disponibilidade de nutrientes, oxigênio, espaço, exigências de manutenção, inviabilizando que o crescimento se mantenha apenas na primeira fase exponencial. O objetivo do trabalho foi verificar possível aplicabilidade do Programa Prático para Modelagem de Curvas (PPM) para Mazama gouazoubira, este pertencente ao plantel do Centro de Conservação da Fauna Silvestre de llha Solteira (CCFS). Os dados foram tabelados no Excel 2010, transferidos para a PPM e ajustados pelo modelo matemático de Richards: $\mathbf{y}=\mathbf{a}\left[\mathbf{1}+(\mathbf{b}-1) \mathrm{e}^{-\mathrm{c}(\mathrm{x}-\mathrm{d})}\right]^{1 /(1-b)}$, sendo o input a idade do animal em dias e o output, o peso em $\mathrm{kg}$. É descrito na literatura, como um facilitador que proporciona um conceito fundamental para 0 estudo do crescimento animal ou qualquer sistema biológico.

A idade do animal não nos permite encontrar os pontos F1, Fi e F2 e F3 na curva, porém nota-se que tende a continuar crescente se as condições seguirem favoráveis. Mostra também a aplicabilidade do programa para a espécie, tornando possível acompanhar o desenvolvimento do animal, visto que pesquisas com dietas e crescimento de animais silvestres em cativeiro ainda são excassas na literatura.

Palavras-chave: força do crescimento; modelagem matemática; veado catingueiro.

\section{INTRODUÇÃO}

O Mazama gouazoubira (Fischer, 1814) distribui-se por todos os biomas brasileiros, exceto a Amazônia (Duarte 1996; Black-Décima et al. 2010; Antunes, 2012), são animais solitários, elusivos, territorialistas (Putman, 1998;
Antunes, 2012) com altura média de 58 $\mathrm{cm}$ e peso entre 11 e $25 \mathrm{~kg}$ (BlackDécima et al. 2010; Antunes, 2012). São considerados generalistas, consomem raízes, flores, frutos, sementes, folhas de ávores e arbustos (Bodmer, 1991; Richard e Juliá, 2001; Gayot et al. 2004; Antunes, 2012). Apesar de ser 
enquadrado na categoria LC (pouco ameaçado) da IUCN Red List, é espécie-chave na estruturação da comunidade de plantas, uma vez que a alteração em sua densidade pode modificar a estrutura dessa comunidade, podendo comprometer a disponibilidade de recursos para as demais espécies de herbívoros (Feldhamer e McShea, 2012; Antunes, 2012).

Descrever o crescimento não é tarefa fácil, os processos bioquímicos demandam tempo, pois em sua dinâmica ocorrem mudanças de tamanho, formato e proporções. Podese considerar que esse processo, apresenta quatro fases: 1- crescimento exponencial; 2- crescimento linear; 3crescimento decrescente; 4- peso estabilizado (adulto). Para justificar os diferentes comportamentos da curva, considera-se limitações nos recursos como: disponibilidade de nutrientes, oxigênio, espaço, exigências de manutenção, inviabilizando que o crescimento se mantenha apenas na primeira fase exponencial (Lawrence e Fowler, 2012; Garcia-Neto, 2018).

Garcia-Neto, 2018 batizou a "força do crescimento/growth fource" como "força ontogênica metabólica" e seu desdobramento em "força ontogênica do crescimento" e "força ontogênica da manutenção".

O processo de crescimento ontogênico pode ser definido como, o desenvolvimento do animal desde a massa do nascimento à massa da maturidade. O catabolismo responsável pela manutenção do tecido já existente, e o anabolismo pela deposição de uma nova biomassa, fornecem uma visão geral do aumento da massa em função do tempo. Entretanto, com o decorrer do desenvolvimento cada vez mais energia é destinada à manutenção do organismo, ou seja, o ganho é resultado líquido da força metabólica.

O objetivo do trabalho foi verificar possível aplicabilidade do Programa
Prático para Modelagem de Curvas (PPM) para Mazama gouazoubira, este pertencente ao plantel do Centro de Conservação da Fauna Silvestre de Ilha Solteira (CCFS).

\section{MATERIAL E MÉTODOS}

Os dados foram tabelados no Programa Prático de Modelagem de Curvas (PPM), disponível gratuitamente (https://goo.gl/rzCjGV), e ajustados pelo modelo matemático de Richards: $\mathbf{y}=\mathbf{a}$ $\left[1+(b-1) e^{-c(x-d)}\right]^{1 /(1-b)}$, sendo 0 input $a$ idade do animal em dias e o output, 0 peso em $\mathrm{kg}$.

A dieta inicial é composta por: $150 \mathrm{ml}$ de leite bovino, 1 medida de PetMilk, $1 \mathrm{ml}$ de cálcio e $1 \mathrm{ml}$ de vitamina K. O leite é aos poucos substituido pela dieta, composta de: ração equina, abóbora, catalônia, banana, frutos da época (todos os dias), cenoura, beterraba, batata doce e sal (ofertados $3 x$ por semana).

\section{RESULTADOS E DISCUSSÃO}

Na Tabela 1 são apresentados os dados que foram iseridos ao programa em peso por dia.

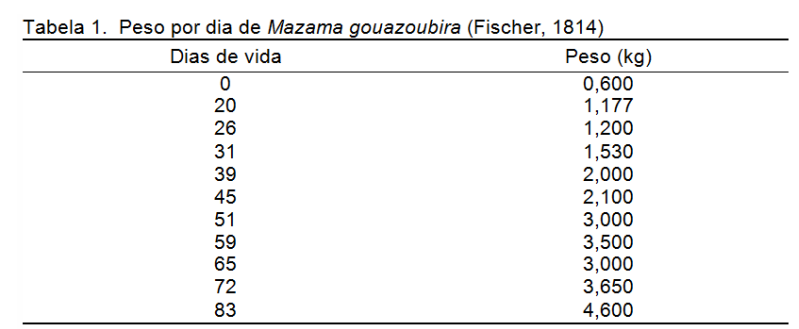

O modelo de Richards é mencionado diversas vezes na literatura como de difícil ajuste em relação a curva, fato devido ao número de parâmetros (quatro parâmetros) e se tentar encontrar simultaneamente os valores dos parâmetros $a, b, c$ e d. (Garcia-Neto, 2018).

É descrita por Garcia-Neto, 2018, o desdobramento da curva em sua primeira e segunda derivadas, que são 
respectivamente velocidade e aceleração, assim encontrado os pontos P1, Pi e P2. Cassiano et al., 2018 relata quatro pontos críticos na trajetória da curva de crescimento: 1. Fase de crescimento exponencial ascendente; 2 . Fase quase linear; 3. Fase exponencial descendente; 4. Assíntota superior de crescimento. Sendo a quarta fase referente a saturação do crescimento, pois o requisito energético para a manutenção impossibilita a síntese de nova biomassa, refletindo na finalização do crescimento animal.

O programa proporciona um conceito fundamental para o estudo do crescimento animal ou qualquer sistema biológico. Também apresenta a possibilidade de identificar os requisitos energéticos para ganho e manutenção e tendo a versatilidade em relação as unidades de medida podendo ser metros, quilos, indivíduos, e outros em relação ao tempo. Assim, quando o valor da força de crescimento ontogênico tende-se para o zero, mais próximo se encontra da maturidade corporal, observando que a força passa pelo zero no ponto de inflexão (Cassiano et al. 2018).

Shimojo et al., 2006, discorre que os três períodos propostos pelo programa PPM se ajustam na curva, sendo eles a chave para a correlação e uma nova abordagem da análise do processo de crescimento (forças metabólicas), podendo-se avaliar a influência favorável ou não da nutrição, genética e ambiência em relação as curvas de crescimento. Na Figura 1, é possível visualizar os parâmetros já citados, e componentes do programa.

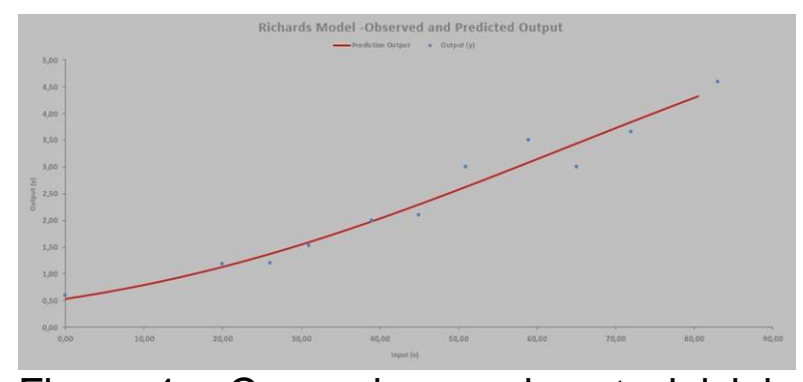

Figura 1. Curva de crescimento inicial de Mazama gouazoubira

A idade do animal não nos permite caracterizar o formato da curva para que o programa defina os pontos, porém nota-se que a curva tende a continuar crescente se as condições seguirem favoráveis para tal. Mostra também a aplicabilidade do programa para animais silvestres, tornando possível acompanhar 0 desenvolvimento do animal, nos permitindo visualizar a necessidade de ajustar dietas, auxiliando a evitar obesidade e acompanhar casos de animais debilitados de uma forma mais precisa, ou seja, utilizando-se como referência a força envolvida no crescimento.

\section{CONCLUSÃO}

Pesquisas com dietas e crescimento de animais silvestres em cativeiro ainda são excassas na literatura, assim o desenvolvimento de programas como o PPM que utiliza modelos matemáticos, podem auxiliar na estimativa e monitoramento do peso, manutenção, qualidade de dieta e da vida dos animais cativos, através da interpretação das curvas de crescimento. Assim, a aplicabilidade do programa demonstrada pode ser muito útil em zoológicos, no acompanhamento diário dos animais visto que a ferramenta é oferecida gratuitamente.

\section{REFERÊNCIAS}

ANTUNES, Vinícius Soares. Área de uso e seleção de habitats por veadocatingueiro (Mazama gouazoubira; 
Fischer, 1814) no pantanal da Nhecolândia-MS. Piracicaba/sp: Esalq Usp, 2012. 75 p.

CASSIANO, Rodrigo Pereira et al. DESCREVENDO E PREDIZENDO CURVAS DE CRESCIMENTO E FORÇAS METABÓLICAS. Campinas/ sp: Conferência Facta-wpsa Brasil, 2018. Disponível em: <https://sites.google.com/site/programap raticodemodelagem/papers $>$. Acesso em: 20 ago. 2018.

GARCIA-NETO, Manoel. Planilha para modelagem de curvas PPM. Araçatuba/sp: Fmva - Unesp Campus de Araçatuba, 2018. Disponível em:

<https://sites.google.com/site/programap raticodemodelagem/papers $>$. Acesso em: 20 ago. 2018.

GARCIA-NETO, Manoel. Descrevendo e predizendo curvas de crescimento e forças metabólicas. Araçatuba/sp: Fvma - Unesp - Campus de Araçatuba, $2018 . \quad$ Disponível em: <https://sites.google.com/site/programap raticodemodelagem/papers $>$. Acesso em: 20 ago. 2018.

SHIMOJO, Masataka. Introducing Viewpoints of Mechanics into Basic Growth Analysis-(II) Relative Growth Rate compared with Energy in Wave Function. JOURNAL-FACULTY OF AGRICULTURE KYUSHU UNIVERSITY, v. 51, n. 2, p. 289, 2006.
Agradecemos ao apoio da Fundação Araucária e da Coordenação de Aperfeiçoamento de Pessoal de Nível Superior - CAPES na realização do $3^{\circ}$ Workshop de Nutrição de Animais Selvagens.

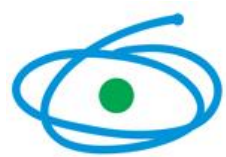

CAPES

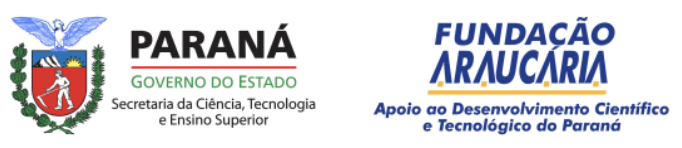

